\title{
WebQuests in Vocational Guidance of School Students with Disabilities
}

\author{
Olga Rodina ${ }^{1, *}$, Liubov Gladkova ${ }^{2}$, and Inga Patrusheva ${ }^{2}$ \\ ${ }^{1}$ Department of Foreign Languages, Tyumen industrial university, Tyumen, Russia \\ ${ }^{2}$ Department of General and Social Pedagogy, Tyumen State University, Tyumen, Russia
}

\begin{abstract}
This article highlights the problem of the vocational guidance of school students with disabilities. Particular attention is paid to a crucial role of a web quest as an educational technology in increasing the motivation of school students with disabilities to enter the university, and facilitating the process of choosing the future profession. It is proved that the systematic application of the WebQuest based technology in the vocational guidance contributes to the development of reflection in school students with disabilities and limited health opportunities.
\end{abstract}

\section{Introduction}

Nowadays vocational guidance represents a scientifically based and pedagogically developed practice that helps school graduates with the professional and life choice. As studies show, miscalculations in choosing a profession, building an individual educational trajectory and a professional career turn out to be a loss of time for students, disappointment and excessive material expenses. In addition, the society loses the most capable and motivated employees who, with the right professional choice, could make a significant contribution to the development of the country's economy.

Today according to UNO experts, the number of people who have acquired a disability due to social, economic, demographic or other reasons is increasing. Every year in Russia, about 3.5 million people are recognized as disabled. According to official statistics, in Russia there are currently 12.1 million people with disabilities (data as of 13.04.2018), which is $8.2 \%$ of the total population of the country. In 2016, there were more than 1 million first-year university students, among which there were only $0.5 \%$ of ones with disabilities considering the fact that $72.2 \%$ of children with disabilities attend a general education school. Graduates with limited health opportunities face additional difficulties in the career orientation. Problems are most often caused by external circumstances such as the lack of readiness of the vocational education system and employers to include a person "with peculiarities" in the labor and educational activities. Social barriers are most often represented by a narrow range of profession choice and workplace, an insufficient awareness of disabled children and their families about training and employment opportunities in accordance with health problems, a low competitiveness in the labor market. In addition, many people with disabilities are poorly adapted in the social environment, they often have a limited range of social relations, they are often passive in the construction and implementation of life plans and they are not flexible enough in educational and professional activities. Therefore, a well-structured and scientifically based system of career-oriented work and subsequent support in obtaining professional education is necessary for this category of citizens. For university students with disabilities as well as school students, it is important to be able to relate their capabilities to the requirements of the profession, to choose the field of activity in which compensation of restrictions and maximum utilization of the available potential is possible. It is important to help graduates to know themselves, to determine the range of demanded professions, to study the educational market, the requirements set by professional educational institutions.

\subsection{Theoretical background}

The researchers (E. A. Petrova, V. V. Pchelinova, D. A. Dzhafar-zade, A. V. Kapriluyuk, 2016) note that for the most effective self-realization and socialization of people with disabilities it is important to obtain general and professional education as an integral condition for successful personality formation and a full participation in the life of society [1].

Nowadays almost every school and institution of secondary vocational education and higher education institutions are engaged in vocational guidance [2, 3, 4 etc].

WebQuest technology is considered today as a fundamentally new organization of the educational process, a modern didactic of teaching and learning. The study of the educational effects of this technology is of

* Corresponding author: o_rodina2605@mail.ru 
great concern among domestic (L.O. Afanasyeva, E. A. Parechnaya, A. A. Karavka, A. F. Levitskaya, A. V. Fedorov, T. O. Lechkina, M. N. Kicherova, G. Z. Elfimova etc) and foreign researchers ((A. A. Yenmez, İ. Özpinar, S. Gökçe, Chang, Cheng-Sian, Chen, TzungShi, Hsu, Wei-Hsiang, Segers, Eliane, Verhoeven, Ludo Kleemans, Tijs, Segers, Eliane, Droop, Mienke, Orlando Gomez, Jose, Perez, Leika, de Lima Tercariol, Adriana Aparecida; Deborah Zaduski; Jeong Cir; de Oliveira Mello; Fernanda Sutkus, etc.)

The researchers considered the psychological and socio-pedagogical aspects of the quest application in school education (L. O. Afanasyeva, A. A. Karavka, A. F. Levitskaya, A. V. Fedorov), underlined a special educational value of the quest-project activity within the educational institution (T. O. Lechkina), substantiated the priority functions of quests such as educational, socializing, adapting to a new space and time and revealed the limitations, possibilities and prospects of quests as social and pedagogical technology for the educational space of the university (M. N. Kicherova, G. Z. Elfimova) [5-8].

The researchers all over the world paid much attention to studying the influence of web quests on the academic achievements of students and the motivation of teaching (A. A. Yenmez, İ. Özpinar, S. Gökçe), the possibilities of using WebQuests resources in teaching in special elementary education and in high school (Segers, Eliane; Verhoeven, Ludo), the features of WebQuests design (O. Gomez, Jose, Perez, Leika), the possibilities of the WebQuests in joint training (De L. Tercariol, A. Aparecida, D. Zaduski etc) [9-12].

However, the development of new technologies for vocational guidance in the context of inclusive education remains a significant scientific and practical task.

\section{Method}

The purpose of this study is the scientific justification and the development of mechanisms for implementing a WebQuest technology in the vocational guidance of school students with disabilities.

\subsection{Hypothesis}

It is assumed that the systematic application of the WebQuest based technology in the vocational guidance contributes to the development of reflection in school students with disabilities and limited health opportunities. Also, it significantly increases the motivation to enter the university and facilitates the process of choosing the right future profession in accordance with the capabilities of school students with different types of nosology.

\subsection{Participants}

In the present study participants were university students-volunteers from the Pedagogical institute and school students with disabilities and limited health opportunities (visual impairment, hearing impairment, disability of the musculoskeletal system) from secondary schools in Tyumen, in Russia.

\section{WebQuest based technology}

This study examines the possibilities of using a WebQuest based technology in the vocational guidance with the school students with limited health opportunities.

This technology is a system of web quests that are goaloriented for students with disabilities and limited health opportunities. First, it is to determine the individual career guidance trajectories. Secondly, it is to expand the understanding of the world of work and their personal characteristics. Thirdly, it is to increase motivation and awareness of the choice of a profession, and develop the creative potential of each student.

WebQuest technology is based on the regularities of interactive learning which is wide spread in modern schools. University students-volunteers come into direct communication with each school student and help to fulfill tasks. At the same time, school students interact with each other and with their assistants both in the real and virtual educational space. The essence of vocational guidance using such technology is that all studentsvolunteers and school students are involved in cognitive creative activity. During this activity they have an understanding of their capabilities and professional interests. The process takes place in a favorable atmosphere with mutual trust and support, which is especially important in the organization of inclusive education.

\subsection{WebQuest structure}

The WebQuest is structured as: 1. Welcome page. 2 . Basic block. 3. Feedback block.

\subsection{Welcome page}

On the welcome page the students get acquainted with the purpose of the web quest, the instructions how to complete tasks. They download an individual participant's page which is filled in as the tasks are completed.

\subsection{Basic block}

The school students get acquainted with general information about the main professional orientations, the concepts "profession", "specialty", etc. One of the tasks of the individual route is the self-diagnosis by defining the leading type of professional activity, the school student's interest in a certain type of work by the method of D. Klimov. Based on the results of testing, they learn relevant information about the type of professional activity, they get acquainted with professiograms. According to the results of the diagnostics, the school students pass to the list of suitable professions. Each participant of the quest has 
the opportunity to choose a role-profession for the task and the situation of living in the profession. If the task is successfully completed, a variant of the list of vocational schools is proposed. If the task is not successfully completed, it is proposed to change the profession and make another choice. In the "Information stand" block students are offered various links to Internet sources according to the criteria: "sites where you can go through additional testing procedures", "Sites dedicated to the description of various professions", "Sites telling about organizations of higher and secondary vocational education ".

\subsection{Feedback block}

It is created to receive feedback from school students who have completed the web quest. In the process of passing the quest, students can try themselves in a certain profession; "feel" their role in a specific professional activity, which contributes to a more conscious choice of the future profession. Such conditions greatly ensure the processes of selfdevelopment, reflection, internal work, evaluation of the possibilities of one's self, professional and educational reflection, understanding of one's life position (K. A. Albulkhanova-Slavskaya, S. G. Vershlovsky and others).

\section{Requirements}

When developing and implementing this technology, special educational needs of students with visual impairment, hearing impairment, disability of the musculoskeletal system, the specificity of work with disabled children (home learning, orientation to individual work, unlimited temporary use of Internet sources) must be taken into account.

To ensure the availability of the WebQuest technology for school students with disabilities and limited health opportunities, special technical training tools and software must be used. They are, for example, screen access programs, equipment designed to improve the auditory perception of speech and the transmission of audio information, etc.

This technology does not require special didactic materials, but requires either smart phones, tablets, or a computer class with access to the Internet.

In the development of career-oriented web quests, it is important to take into account the characteristics of the labor market of the region and fill in the content of the quest with information on popular and available professions for people with disabilities and limited health opportunities.

\subsection{Criteria}

Criteria for assessing the effectiveness of the technology: an increase in the proportion of 8-11 grade students with disabilities and limited health opportunities determined with the choice of the profession (based on diagnosis and questioning); an increase in the proportion of school students enrolled in higher education. Efficiency was tested in the experimental groups during the year (from 2016-2017).

\section{Discussion and Conclusion}

During the WebQuest, students with disabilities and health limitations are offered general information about professions and specialties. One of the tasks of the individual route is self-diagnostics that help to determine the school student's interest in a certain type of work, then the leading type of professional activity. To sum up, school students have the opportunity to try various kinds of professional activities, to determine what they like to do more, what they are strong, and where they have difficulties.

The educational WebQuest technology in the vocational guidance provides an additional opportunity for professional expertise of creative abilities of persons with disabilities and limited health opportunities, taking into account their special needs and potential for the professional self-realization.

The universality of this form of vocational guidance is that it can be used in any professional educational organization and in remote interaction with participants. Tasks can vary depending on the direction of professional orientation and focus of VET.

Innovation of technology is to intensify the reflection development processes, which is understood as a set of intellectual skills, concepts functionally associated with self-awareness and aimed at understanding and solving practical, including professional tasks, to generalize and compare the information received and the student's own activity in an inclusive higher education. A career-oriented WebQuest as a form of activities is understandable and relevant for children and adolescents. The WebQuest is conducted in a game form creating a free and independent communication environment. It enables each participant to manifest themselves. The game creates a creative atmosphere, through which the participants of the quest have the opportunity to identify and demonstrate their hidden talents and abilities. Carrying out various tasks, participants need to make the right decisions, draw the right conclusions, carry out actions of a professional orientation, which immerses them in the world of professions and helps to identify and determine their professional preferences. The participation of students-moderators in the process of the game attracts the attention of school students, removes the age barrier and promotes the creation of conditions for interaction, cooperation and mutual understanding.

\section{References}

1. E. A. Petrova, V. V. Pchelinova, D. A. Dzhafarzade, A. V. Kapriluyuk, Labour and vocational guidance of persons with disabilities: textbook. (Publishing house RGSU, 2016) 
2. Ş. Külahoğlu, Procedia - Social and Behavioral Sciences 1(1), 2001-2006 (2009)

3. A. Ghergut, Procedia - Social and Behavioral Sciences 114, 116-120, (2014)

4. C. Carvalho, D. Martins, Lidia E. Santana, L. Feliciano, Procedia - Social and Behavioral Sciences 159, 219-223 (2014)

5. L. O. Afanasyeva, E. A. Porechnaya School technology 6, 149-159 (2012)

6. A. Karavka, World of Science 3, 20 (2015)

7. T.O. Lechkin, Science and education: a new time. 1(6) 12-14 (2015)

8. M. N. Kicherova, G. Z. Efimova, Internet-journal "The World of Science" 4(5) (2016)

A. A. Yenmez , İ. Özpinar , S. Gökçe Universal Journal of Educational Research 5, 1554-1570 (2017)

9. S. Eliane; V. Ludo, Learning and Instruction, 19(5), 423-432 (2009)

10. J. O. Gomez, L. Perez, Eduweb-Revista De Technologia De Information y Comunication En Education 10(1), 55-56 (2106)

11. De L. Tercariol, A. Aparecida, D. Zaduski, 7th International Conference on Education and New Learning Technologies (EDULEARN) (Barcelona, SPAIN, 2015) 